\title{
LA INFLUENCIA TARDO-LATINA EN LA LENGUA VASCA: EL ORIGEN TARDO-LATINO DE LA ESTRUCTURA MORFOLÓGICA VERBAL ANALÍTICA VASCA A TRAVÉS DE LOS VERBOS ADITU Y SORTU
}

\author{
José Fernando Domene VERdú \\ Alicante
}

\section{RESUMEN}

La influencia latina en la lengua vasca fue muy importante, y una de las consecuencias de ello fue la aparición de la Estructura Morfológica Verbal Analítica vasca (EMVA). Frente a la hipótesis tradicional de su mayor antigüedad con respecto a la Estructura Morfológica Verbal Sintética (EMVS), se acepta actualmente que esta última es la más antigua de la conjugación vasca y que la estructura analítica apareció por influencia del latín, como ya apuntó Michelena. En el presente artículo se demuestra, a través de dos verbos de origen latino (uno transitivo, aditu = 'oír, oído', y otro intransitivo, sortu = 'nacer, nacido'), que la EMVA apareció por analogía con la EMVA del latín tardío, con el fin de poder conjugar los verbos de origen latino introducidos masivamente en vasco como préstamos lingüísticos, y que es del todo coincidente con la EMVA tardo-latina que le sirvió de modelo. Los verbos de origen latino se introdujeron en vasco en participio (con el sufijo - $t u$ ), y no en infinitivo, porque lo hicieron junto a la EMVA tardo-latina, sustituyendo el verbo auxiliar latino por su equivalente en vasco según la cualidad transitiva o intransitiva del verbo principal (HABĒRE se sustituyó por ukan y ESSE por izan). La primera EMVA que surgió en vasco fue la del pretérito perfecto de indicativo, en todo análoga a la tardolatina. Más tarde, y por analogía con ella, se formaron las EMVA de los demás modos, tiempos y aspectos, así como la voz pasiva. Los modos subjuntivo, imperativo y potencial utilizaron unos verbos auxiliares distintos a los del modo indicativo para diferenciarse de él. La nueva EMVA, además, fue sustituyendo progresivamente a la antigua EMVS en la mayoría de los verbos autóctonos, incluso en presente y pasado de indicativo.

Palabras clave: Lengua vasca, latín tardío, morfología verbal, estructura analítica, estructura perifrástica.

\section{ABSTRACT}

The Latin influence in the Basque language was very important, and one of its consequences was the formation of the Basque Verbal Analitical Morphological Structure (EMVA). Against the traditional hypothesis that considered EMVA to be older than the Basque Verbal Synthetical Morphological Structure (EMVS), it is actually accepted that EMVS is in fact the oldest. Basque conjugation and the EMVA appeared because of the influence of latin, as Michelena proposed. In this article, 
I prove that the Basque EMVA appeared by analogy with the EMVA of Late Latin in order to be able to use the Latin verbs that entered in Basque language as loanwords, and so the Basque EMVA is analogous to the Late Latin one, which served as its pattern. To argument it, I use two verbs of Latin origin, one of them transitive, $a d i t u=$ 'to hear, heared', and the other one intransitive, sortu = 'to born, borned'. Latin verbs entered in Basque in the Participle form (with the suffix -tu), not in the Infinitive, and together with the Late Latin EMVA, but changing the Latin auxiliary verbs by their equivalent in Basque (HABĒRE by ukan and ESSE by izan). The first Basque EMVA to appear was the one of the Perfect Past of Indicative, which is analogous to the Late Latin one. Later, the EMVA of the other modes, tenses and aspects, and also the passive EMVA, were formed in Basque by analogy with the EMVA of Late Latin, but in the EMVA of the Subjunctive, Imperative and Potential modes were used auxiliary verbs different from Indicative in order to differentiate those modes from this one. Later, the old EMVS was being replaced by the new EMVA in the most of Basque verbs, even in the Present and the Past tenses.

Key Words: Basque language, Late Latin, verbal Morphology, analytical structure, periphrastic structure.

La morfología verbal ha constituido, sin duda, el mayor centro de atención de los lingüistas que se han ocupado de la lengua vasca, debido a su riqueza y a su complejidad, pero a la vez a su asombrosa regularidad $^{1}$. Prácticamente todos los gramáticos y los lingüistas que se han ocupado de la lengua vasca, desde A. d'Oihenart 1638 y R. Micoleta 1653, lo han hecho también del verbo y, dentro del amplísimo campo de la morfología verbal vasca, han suscitado especial interés las formas analíticas o perifrásticas y su mayor o menor antigüedad con respecto a las sintéticas. La opinión tradicional más generalizada consideraba la estructura analítica del verbo vasco más antigua que la sintética y que esta no era sino una corrupción de aquella. Esta postura fue defendida por M. de Larramendi 1729, M. Harriet 1741, P. P. Astarloa 1803, A. Th. d'Abbadie y J. A. Chaho 1836, J. P. Darrigol 1827, E. T. Inchauspe 1858, L. L. Bonaparte 1869 y A. Campión 1884, principalmente. M. de Larramendi 1729 vio incluso el origen de los tiempos compuestos de las lenguas romances en la imitación de la estructura analítica vasca porque, según él, estos no existían en latín ni en griego y sí, en cambio, en la lengua vasca, que es más antigua que las anteriores (cit. Azcarate y Altuna 2001, pp. 151-152). Por el contrario, A. d'Oihenart 1656 consideró

\footnotetext{
1 Estas características son las propias de las lenguas de tipo aglutinante, de las que la lengua vasca es un ejemplo paradigmático. Por eso ha atraído también la atención de los lingüistas, nacionales y extranjeros, interesados en la tipología de las lenguas y por su posible parentesco con otras familias lingüísticas, desde W. Von Humboldt 1821, L. L. Bonaparte 1869, W. J. Van Eys 1879, H. Schuchardt 1893, 1923, R. M. de Azkue 1905-1906, 1923-1925, G. Lacombe 1924, H. Gavel 1937, R. Lafon 1943, 1960, 1973, P. Laffite 1944, L. Michelena 1961, 1964 y, más recientemente, P. de Yrízar 1981 o R. L. Trask 1977, 1981, 1990, 1995, por solo citar algunos.
} 
la estructura sintética vasca como conjugación propia y la analítica como impropia. En esta misma línea, prácticamente todos los lingüistas del siglo xx han defendido la mayor antigüedad de la estructura sintética, sobre todo desde que R. Lafon 1943 descubrió que en los textos literarios del siglo XVI se empleaban 60 verbos con estructura sintética y que ese número se ha ido reduciendo de forma drástica hasta los dos únicos verbos (izan y ukan) que la conservan en la actualidad en la lengua hablada. L. Michelena 1964, 1987b [1981] confirmó esta misma tesis, atribuyendo el origen de la estructura analítica vasca a la influencia romance dentro de la tendencia general que se ha observado en otras lenguas europeas occidentales (por ejemplo, etorri $d a=$ cast. ant. es venido $=$ fr. est venu $=$ al. ist gekommen; egin $d u=$ cast. ha hecho $=$ fr. a fait $=$ al. hat gemacht; joango $d a=$ cast. ant. es de ir; egingo $d u=$ cast. ant. ha de hacer). La mayor antigüedad de la EMVS con respecto a la EMVA es lo que se acepta generalmente en la actualidad ${ }^{2}$.

Es posible demostrar de una forma clara el origen de la estructura analítica vasca a partir de la influencia de las lenguas romances de la mano de algunos verbos vascos que, procedentes del latín, entraron en una época muy temprana y lo hicieron en participio, no en infinitivo. Esto implica que tuvieron que introducirse en vasco junto con la estructura analítica del latín vulgar y del latín tardío. Uno de estos verbos es aditu = 'oír, escuchar; oido, escuchado', que procede del participio latino AUditu $(\mathrm{M})$ = 'oido' y se introdujo en vasco en época muy temprana, porque ha conservado la oclusiva dental sorda / $/$ y la oclusiva dental sonora / $\mathrm{d} /$ intervocálicas, habiendo reducido a /a/ el diptongo [au] en posición inicial, en vez de a /o/ como en las lenguas románicas (oír, etcétera).

En cuanto a la cronología relativa de las estructuras morfológicas verbales (EMV), es lógico admitir que toda EMV incluida en otra EMV más compleja es más antigua que la EMV que la incluye. Como la estructura morfológica verbal sintética (EMVS) forma parte necesariamente de la estructura morfológica verbal analítica (EMVA) ${ }^{3}$ y está incluida en todos

\footnotetext{
2 «In earlier centuries and up to the beginning of ours, researchers thought, almost unanimously, that the ancient Basque verb had only analytical (periphrastic) forms, simple or synthetic foms being a corruption of those (Astarloa 1803, Bonaparte 1869, d'Abbadie and Chaho 1836, Darrigol [1827], Harriet 1741, Inchauspe 1858, Larramendi 1729, among others). Oihenart 1656 [1638] is the most notable exception to this current of thought (see Gómez 1989, p. 361). Today, in contrast, there is universal agreement that the handful of verbs which have synthetic forms preserve a state of affairs which must have been much more general in older times. In fact, old texts presents a greater number of verbs with synthetic forms than are currently used. Nevertheless, the system of analytical forms with an auxiliary appears as perfectly consolidated even in the earliest texts» (Gómez y Sainz 1995, pp. 237-238).

${ }^{3}$ La Estructura Morfológica Verbal Analítica (EMVA) está formada, al menos, por dos verbos, el verbo principal en participio y el verbo auxiliar conjugado, y este último puede tener, a su vez, tanto una Estructura Morfológica Verbal Sintética (EMVS) como una EMVA. Uno de
} 
los demás tipos de EMV vascas, se puede concluir que la EMVS es más antigua que la EMVA y, a su vez, que la EMVA es más antigua que la estructura morfológica verbal perifrástica (EMVP) ${ }^{4}$. O, lo que es lo mismo, como toda EMV que incluye otras EMVS más sencillas es más moderna que todas las EMV que incluye, se puede concluir que la EMVP es más moderna que la EMVA y, a su vez, que la EMVA es más moderna que la EMVS. Así, por ejemplo, es evidente que $n$-a-tor = 'yo vengo' es más antiguo que etor-ten naiz = 'yo suelo venir'. Pero es más evidente todavía que $n$-a-tor = 'yo vengo' (EMVS) es más antiguo que la expresión $e$-torr- $i$ $n$-a-tor $=$ 'yo estoy viniendo' $=$ 'yo vengo viniendo' (EMVA) porque está incluida en ella, ya que la EMVA del presente continuo utiliza el mismo verbo principal también como auxiliar. La mayor antigüedad de la EMVS con respecto a la EMVA la confirman, por una parte, los mismos conceptos de verbo auxiliar y verbo principal ${ }^{5}$. La duplicidad de tiempos y modos verbales en la EMVS y la EMVA (el presente y el pasado se pueden expresar mediante ambas EMV) también confirma esta cronología ${ }^{6}$. Es

los verbos que forman la EMVA es el que contiene la significación y, por tanto, actúa como lexema y es el verbo principal, mientras que las demás formas verbales de la EMVA carecen de significación y corresponden solo a una o a varias funciones verbales, actúan como morfemas independientes; son los verbos auxiliares, y en ellos residen normalmente todas las funciones verbales (persona, número, caso, tiempo, modo, voz, etc.). En la EMVA de los tiempos perfectos de las lenguas románicas, los verbos auxiliares haber y ser carecen de significación pero, en cambio, son los que expresan todas las funciones verbales y solo las funciones verbales. La anterior definición de EMVA proporciona muy poca información sobre sí misma y sobre los elementos que la componen, porque no toda EMV que esté formada por varios verbos es una EMVA, sino que tienen que cumplir unas determinadas condiciones como, por ejemplo, que uno de esos verbos posea el significado y esté en una forma nominal, y que los demás verbos posean todas las funciones de la EMV pero carezcan de significado, es decir, que tengan un verbo principal y, al menos, un verbo auxiliar.

${ }^{4}$ Para simplificar la exposición, convendremos en representar la Estructura Morfológica Verbal por las siglas EMV y por SMV el Sistema Morfológico Verbal o Paradigma al que corresponde una EMV. La EMV vasca puede ser de dos tipos: EMV sintética, que representaremos por las siglas EMVS, y EMV analítica, que representaremos por las siglas EMVA. A ambas EMVS, se les puede añadir una tercera, la EMV perifrástica, que corresponde a las perífrasis verbales y representaremos por las siglas EMVP. Los cambios fonéticos se expresan mediante las siglas CF (Domene 2009).

${ }^{5}$ El concepto de verbo auxiliar indica que un verbo, llamado verbo principal, le cede a otro verbo distinto, como izan o ukan, la capacidad de expresar sus funciones gramaticales pero no su significado, que sigue conservando, mientras que el verbo que expresa las funciones gramaticales de otro, el verbo auxiliar, pierde su significado propio y solo expresa esas funciones gramaticales del verbo al que acompaña. Esta EMVA formada por un verbo principal y un verbo auxiliar es más moderna que la EMVS del verbo auxiliar incluido en ella porque presupone, evidentemente, la existencia previa de la EMVS de dicho verbo auxiliar (Domene 2009).

${ }^{6}$ La EMVA expresa algunos tiempos y modos que ya expresaba la EMVS, y lo mismo ocurre con la EMVP, que expresa también algunos tiempos y modos que ya expresaban tanto la EMVS como la EMVA, con lo que esos tiempos y modos se pueden expresar de varias maneras diferentes, con una cronología diferente cada una de ellas. Se ha originado, con ello, una duplicidad que se explica por esa diferente cronología de las distintas EMV vascas, según la cual la EMVS es más antigua que la EMVA y esta es más antigua que la EMVP (Domene 2009). 
evidente, por tanto, que la EMVS es más antigua que la EMVA y que esta apareció antes que los primeros textos vascos, es decir, antes del siglo XVI, que sería el terminus ante quem. El terminus post quem se puede confirmar o establecer analizando lo que realmente ha supuesto la EMVA en la EMV vasca y la necesidad de su aparición.

Se puede observar en efecto que, en los verbos que poseen EMVS, la EMVA solo presenta la ventaja de poder expresar algunos tiempos, modos y aspectos que no se pueden expresar con la EMVS, aunque se trata de tiempos, modos y aspectos secundarios, no de los fundamentales. Por eso, esos verbos con EMVS podrían prescindir de la EMVA si solo tuvieran que expresar esos tiempos fundamentales (presente, pasado e imperativo). La EMVA es imprescindible, por el contrario, en los verbos que carecen de EMVS, porque entonces la EMVA es la única que puede expresar sus funciones gramaticales. Por ejemplo, el verbo hurbildu= 'acercarse' no puede expresar por sí mismo sus funciones gramaticales porque carece de EMVS, ya que se ha formado al añadirle el sufijo $-t u>-d u$ al adverbio-adjetivo hurbil = 'cerca'. Por eso, solo puede expresar sus funciones gramaticales por medio de otro verbo que sí posea EMVS, como es izan = 'ser', y funcione como auxiliar perdiendo su significado. En hurbil-du n-a-tza-i-o = 'yo me he acercado a él/ella/ello', por ejemplo, el sujeto 'yo' lo expresa el prefijo $n$-, el tiempo presente lo expresa el infijo $-a-$, el objeto indirecto de $3^{\underline{a}}$ pers. sing. lo expresa el sufijo - o del verbo auxiliar izan, mientras que el significado del verbo, 'venir', lo expresa la raíz hurbil- del verbo principal hurbil-du = 'acercado'. El verbo hurbildu = 'acercarse' se formó, por tanto, a partir del adverbio-adjetivo hurbil = 'cerca' que, al no ser un verbo, carecía de EMVS y no podía expresar por sí mismo todas esas funciones. La formación de una EMVS propia de ese nuevo verbo hurbildu hubiera sido posible. Sin embargo, la formación de EMVS para un gran número de nuevos verbos en un corto espacio de tiempo hubiera resultado un proceso excesivamente difícil de llevar a cabo, dada la complejidad de la EMVS vasca. Por lo tanto, la única manera de poder expresar las funciones gramaticales de los nuevos verbos sería mediante otro verbo que ya tuviera una EMVS propia. Por ello, la EMVA se tuvo que formar en un momento histórico en el que apareciera en el léxico vasco un gran número de verbos nuevos, un aluvión de nuevos verbos que impidiera formar un Sistema Morfológico Verbal (SMV) sintético para cada uno de ellos y obligara a utilizar con ellos el SMV de otro verbo, es decir, un SMV analítico y la consiguiente EMVA. Este aluvión de nuevos verbos, acompañado de otras nuevas palabras en general, tuvo que deberse a la influencia de otra lengua.

El primer aporte léxico a la lengua vasca conocido se debió a las lenguas celtas, pero la influencia latina fue mucho más importante, como ya se ha puesto de manifiesto (Michelena 1974, pp. 183-209; 1987, pp. 
195-219). El primer gran aporte léxico a la lengua vasca se debe, por tanto, a la influencia latina y, posteriormente, a la de las lenguas romances más próximas al territorio vasco. Se puede observar que ninguno de los verbos vascos de origen latino o romance formó un SMV sintético propio, excepto ezagutu = 'conocer' como un caso excepcional perfectamente explicable ${ }^{7}$. Los verbos latinos no se pudieron introducir en infinitivo porque en el léxico vasco no hay ni rastro del sufijo de infi-

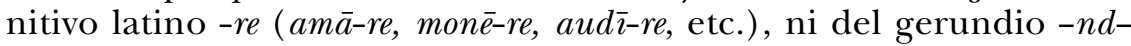
( ama-nd-um, mone-nd-um, audie-nd-um, etc.), ni de ninguna otra forma verbal personal o impersonal, porque tampoco hay rastro de otros sufijos verbales, salvo el sufijo de participio pasado masculino -tu (por ejemplo, am $\bar{a}-t u-m$, $a u d \bar{\imath}-t u-m$, etc.). En efecto, los verbos vascos de origen latino llevan el sufijo de infinitivo/participio - $t u$, que es de origen latino y procede del sufijo de participio pasado masculino -tu (ama-tu-m, $a u d \bar{\imath}-t u-m$, etc.). Por eso, el sufijo - $t u$ tuvo que introducirse en vasco junto con los verbos latinos en participio y en alguno de los usos sintácticos de dicho modo impersonal. Sin embargo, teniendo en cuenta que su uso principal en vasco ha sido como participio en el verbo principal de la EMVA, parece bastante evidente que se tuvo que introducir en vasco formando parte de la EMVA. A partir de ahí, solo se tuvo que sustituir el verbo auxiliar latino por el verbo vasco correspondiente para dar lugar tanto a la EMVA vasca como al sufijo -tu. Por lo tanto, tuvo que ser la influencia latina la que forzara la utilización de la EMVA vasca para poder conjugar los abundantísimos préstamos latinos que se introdujeron como verbos en el léxico vasco. Y los verbos de origen latino se

\footnotetext{
${ }^{7}$ El verbo ezagutu 'conocer' es conjugable y de origen romance, según han admitido Schuchardt 1947 [1923], p. 78, Lafon 1943, I, p. 422 y Michelena 1947 [1974], p. 215. La raíz -zagu- estaría relacionada con el participio del verbo «saber», que en catalán es sabut 'sabido, conocido'. Es muy normal también en catalán la sustitución de $b$ o $v$ por /g/ en los participios y también en otros tiempos verbales ante la / $\mathrm{u} /$ típica de la $2^{\underline{a}}$ conjugación, que procede de la /i/ original latina (Ej.: lat. * habitu > cast. habido, cat. hagut; lat. *bibitu > ${ }^{*}$ bebitu > cast. bebido, cat. begut, etc.). El participio catalán del verbo saber es sabut, por lo que el cambio fonético $b>g$ no se ha producido en este verbo, pero no se puede descartar que se hubiera producido de forma dialectal (sabut $>$ *sagut) en el momento histórico en el que dicho participio entró como préstamo en vasco procedente del romance, lo que explicaría perfectamente la raíz-zagu- del actual verbo vasco ezagutu, que habría entrado en participio sin el prefijo $e-$, que se habría añadido más tarde, concretamente al crearse su EMV sintética (*sagutu > *zagutu > ezagutu $=$ e-zagu-tu). El motivo de haberse conjugado, creando una EMVS específica para él, se puede explicar por su similitud con el verbo auxiliar vasco ezan, que se utiliza en los modos imperativo, subjuntivo y potencial de los verbos transitivos y que en las flexiones de $1^{\mathfrak{a}}$ persona plural de ergativo ( $g u k=$ 'nosotros/-as') y de dativo ( guri= 'a nosotros/-as') presenta precisamente el núcleo -zagu- (-za-gu-), en el que - za- es la raíz de $e z a n$ y - gu- es el sufijo de $1^{\text {a }}$ persona plural de ergativo ( $h$-a-za-gu- $n=$ 'para que nosotros/as te hayamos'; die-za-gu-zu-n= "para que vosotros/as nos lo/la hagáis'). Evidentemente, la raíz de ezagutu (zagu-) se identificó con este núcleo de la EMVS de ezan y la EMV de ezagutu resultó estar ya construida ( $h$-a-zagu- $n$ = 'que (él/ella/ello) te conoce'). Por lo tanto, esta EMV es un caso excepcional y no es en absoluto representativa.
} 
tuvieron que introducir en vasco en participio pasado masculino junto con el sufijo latino $-t u^{8}$, y no en infinitivo ni en gerundio, ya que el sufijo -tu es el único sufijo verbal de origen latino de la lengua vasca y ha sido además muy prolífico, porque ha permitido formar casi infinitos nuevos verbos, añadiéndose a casi cualquier palabra vasca o de origen alóctono ${ }^{9}$. Es significativo el participio vasco aditu = 'oído', que en infinitivo significa 'atender (escuchando o mirando)' en una parte del vizcaíno, 'entender' en la otra parte del vizcaíno, en parte del guipuzcoano y en bajo-navarro, y 'oír' en la otra parte del guipuzcoano y en alto-navarro (Azkue 1905-1906, I, p. 11). Pues bien, este verbo vasco aditu procede del participio latino audìtum = 'oído' mediante el cambio fonético $a u>a$ (Michelena 1961, p. 95) ${ }^{10}$, de manera que su evolución fonética ha sido muy breve porque, aparte de la / m/ final que desapareció muy pronto en latín, solo se ha producido el mencionado cambio fonético $a u>a($ audītum $>$ *auditu > aditu). Esta palabra ha conservado, por tanto, la oclusiva sorda intervocálica /t/, por lo que el préstamo latino se tuvo que introducir en vasco en una fecha muy temprana, antes de que se sonorizaran las oclusivas sordas intervocálicas.

Lo mismo ocurrió con los verbos intransitivos, como por ejemplo el participio vasco sortu = 'nacido', que en infinitivo significa 'nacer' en todos los dialectos, 'concebir' en vizcaíno, 'brotar, surgir' en guipuzcoano y alto-navarro, etc. (Azkue 1905-1906, II, p. 229). El participio vasco sor$t u=$ 'nacido' procede del latino sortum = 'brotado, surgido', combinado con el significado de ortum = 'nacido, salido' y estaría relacionado con el verbo francés, occitano y catalán sortir = 'salir'. La etimología de los verbos castellanos surgir y surtir, procedentes de los verbos catalanes sorgir y sortir, la explica Corominas 1954; 1961, p. 54911. Corominas y Pascual 1980-1991 explican la etimología del verbo sortir como proce-

8 Según Trask, «the suffix - $t u$ is of Latin origin. Early Basque borrowed a very large number of verbs from Latin, and these were borrowed in the form of the perfective participle, which in most Latin verbs ended in $-t u(m)$ : Lat pensatu $>\mathrm{Bq}$ pentsatu 'think', Lat benedicatu > Bq bedeinkatu 'bless', and so on» (Trask 1995, p. 211).

9 En palabras de Azkue, «el sufijo verbal -TU es uno de los más fecundos que pueden concebirse en lengua alguna» (Azkue 1905-1906, I, p. XVIII).

10 «Es frecuente la vacilación $a u$ / $a$, especialmente en sílaba inicial. Parece que esto ha de entenderse la mayoría de las veces como reducción a $a$ del antiguo diptongo (cf. com. aditu 'oído, entendido' < lat. auditum)» (Michelena 1961, p. 95).

11 SURGIR, 1438 (raro hasta el siglo XVIII), 'alzarse, aparecer'. Tom. del lat. sǔrgěre íd. En el sentido de 'estar fondeada' o 'dar fondo', hablando de una nave, princ. siglo Xv, se tomó del cat. sorgir íd., siglo XIII. Este viene probablemente del lat. sŭrgere 'levantarse', en frases como navis surgit in portu 'la nave aparece, se levanta en el puerto', de donde 'está quieta allí, está fondeada', tal como stare 'estar de pie' pasó a 'estar detenido en un lugar'.

SURTIR, siglo XV y quizá ya XIII, 'brotar, saltar (agua, etc.)', 1490; 'proveer de algo', 1590; 'producir (efecto)', 1486. Voz emparentada con el fr., oc. y cat. sortir, que significan o han significado lo mismo, desde los siglos XII-XV, y además 'salir' desde el XVI. Seguramente tomada de estos idiomas. 
dente del latín sŭrgěre combinado con el verbo deponente sortǐrĭ preexistente en latín ${ }^{12}$, y relacionan además el verbo vasco sortu con el verbo catalán-occitano-francés sortir y con el participio latino *surctus del cual proceden ambos ${ }^{13}$ :

Una nova i valuosa confirmació l'aporta el basc sortu 'néixer, originar-se' (Axular, siglo VII, Euskera VI, p. 56), «concebre», «brollar, sorgir», primitivament participi «nascut», «brollat» (Schuchardt, l. c., I Litbl. XXXIX, 43, n. 1).

12 SORTIR, 'resultar', 'brollar', 'eixir: anar de dins a fora', mot comú, en les primeres acepcions, a totes les llengues romàniques, en les quals apareix també, des d'antic, en sentits com «treure a la sort», produir-se com a resultat eventual d'una obra o d'un sorteig', en els quals prové del ll. sortiri id.; en el sentit de brollar, sorgir', i en el d' 'eixir', que és també antic, però peculiar del català, la llengua d'oc y el francès, sembla segur que és degut més aviat a un derivat de l'antic participi surt, surta, de SORGIR (ll. vg. *surctus), que es combinà i es va sumar amb sortir de SORTIRI. $1^{\underline{a}}$ doc. princ. siglo XIV (Muntaner; Consolat, etc.).

[...] es tractaria d'un derivat del participi *sŭrctus de surgere 'sorgir'. A la qual cosa no és veritat que es puguin oposar raons fonètiques ni norfològiques; car és molt versemblant que aquesta forma fos general en llatí vulgar: el clàssic surrectus aviat es degué eliminar (el tipus sors, sorse, no és més que gal-lo-rom., ni allí general, i evidentment secundari), i hem vist la vigorosa supervivència cat.-oc.-it.-hisp. en l'article SORGIR. Una nova i valuosa confirmació l'aporta el basc sortu 'néixer, originar-se' (Axular, S. S VII, Euskera VI, p. 56), «concebre», «brollar, sorgir», primitivament participi «nascut», «brollat» (Schuchardt, l. c., I Litbl. XXXIX, 43, n. 1). Reconeixem, però, que encara que aquest origen sigui teòricament inatacable, la història de sortir en francès, no desmentida per la it. i cat., corrobora també, fortament, l'etimologia sortiri. Tanmateix també és clar que bona part de les accs. del nostre mot (A, B, D, E) i dels deriv. apunten cap a *surctum amb tanta evidència, que obliguen a admetre convergència de les dues filiacions. [...] També en això la presència de *surctum és evident. En conclusió, d'aquí ja s'hauria derivat sortir 'brollar l'aigua', però la preexistència del verb sortiri, bo i format en llatí, va reforçar, sumant-s'hi, aquesta creació.

13 A partir del participio *surctus = 'levantado, surgido' del latín vulgar, correspondiente al infinitivo latino sŭrgěre, se formó el nuevo verbo *surctire, que evolucionó a sortir en las lenguas románicas, ya que la formación de nuevos verbos a partir del participio es un procedimiento muy frecuente en latín (por ejemplo, canto a partir de cantum, supino de cano = 'canto', o el mismo salto = 'danzo' a partir de saltum, supino de salio = 'salto', de manera que tanto salio = 'salto' como su frecuentativo salto = 'danzo' se han conservado en castellano, el primero con el significado de 'salir' y el segundo con el de 'saltar'). De este modo, en latín vulgar aparecieron dos verbos, el normal sürgěre y el frecuentativo *surctire, que se han conservado en las lenguas románicas. Así, en catalán, occitano y francés han originado respectivamente los verbos sorgir y sortir. En castellano, los verbos surgir y surtir (con el significado de 'brotar agua' o con otros como, por ejemplo, surtir efecto) proceden de los verbos catalanes sorgir y sortir, respectivamente. Sin embargo, los tiempos del perfectum, el participio y el supino de los verbos sürgěre $\mathrm{y}$ *surctire se volvieron a regularizar con los tiempos del infectum y con el infinitivo, siguiendo el modelo del verbo rego a partir del cual se formaron. Pero este nuevo verbo *surctire del latín vulgar evolucionó fonéticamente a surtir o a sortir muy pronto, según las leyes fonéticas del mismo latín vulgar, hasta llegar a la forma que presenta actualmente en las lenguas románicas, *sŭrtivi $>$ *sŭrtii $>$ *sortii $>$ sortí $\mathrm{y} *$ sŭrctitum $>$ *sŭrctitu $>$ *sŭrtitu $>$ *sortitu $>$ *sortido $>*$ sortid $>$ sortit en catalán, de donde procede el verbo castellano surtir (sortir $>$ surtir). Su evolución fonética en castellano sería, por tanto, *sŭrtivi $>$ *sŭrtii $>$ *sortii > sortí $>$ surtí $\mathrm{y} *$ sŭrctitum $>$ *sŭrctitu $>*$ sŭrtitu $>*$ sortitu $>*$ sortido $>*$ surtido. En las lenguas románicas, por tanto, se produjo además el cambio fonético $\breve{u}>o$, según la ley fonética correspondiente del latín vulgar (Herman 1997, pp. 37-43). 
Esta etimología del participio vasco sortu con el significado de 'brotar', 'surgir' procedente el participio latino *sŭrctum es posible fonéticamente, pero solo en un momento muy concreto de la evolución histórica de este verbo. En efecto, el participio *sürctus del latín vulgar solo se pudo introducir en vasco una vez que el nominativo *sŭrctus había sido sustituido por el acusativo *sŭrctum en la Estructura Morfológica Nominal (EMN) o declinación y una vez que desaparecieron la consonante $/ \mathrm{k} / \mathrm{y}$ la $/ \mathrm{m} /$ del sufijo $-m$ del acusativo, una vez que la vocal / $\breve{u} /$ se había convertido en /o/ mediante el cambio fonético $\breve{u}>o$ propio del latín vulgar (*sŭrctum > *sortu), pero antes de que este participio *sŭrctus, irregular con respecto al infinitivo y a los tiempos del infectum, fuera sustituido por el nuevo *surgitum > *sorgitu, del que proceden los participios románicos del verbo surgir / sorgir (surgido, sorgit, etc.) y que es regular con el infinitivo y los tiempos del infectum. El verbo *sürctere > sortire, por su parte, se combinó con el verbo sŏrtǐr a suertes, obtener por suerte' (sortior, sŏrtǐrĭ, sortĭtus sum) debido a la evolución fonética del verbo *sŭrctere > sortire, que se igualó prácticamente al deponente sortǐr añadió el significado de este último en catalán, occitano y francés. Por lo tanto, el participio *sŭrctus del latín vulgar solo se pudo introducir en vasco en un momento muy concreto de la evolución de dicho verbo en el latín vulgar: *sŭrctus $>$ *sŭrctum $>$ *sortu $>$ *surgitum $>$ *sorgitu $>$ sorgido > sorgit, surgido.

Esta etimología del verbo vasco sortu es evidente, pero solo para esa acepción, que es la misma que presenta de una manera general el verbo románico sortir. Sin embargo, el significado 'nacer' y 'concebir', que es el principal del verbo vasco sortu y el único común a todos los dialectos, es el mismo que el del verbo deponente latino orior, orǐr = 'nacer', cuyo participio es ortus. La explicación está en la combinación de ambos participios latinos, el participio ortus del verbo orior, orǐr = 'nacer' y el participio *sŭrctus del latín vulgar del verbo latino surgo, sŭrgěre = 'levantarse', con el significado 'brotar, surgir' del verbo románico sortir = 'brotar, surgir', antes de que sortir hubiera tomado en catalán, occitano y francés el significado moderno de 'salir'.

Este participio pasado latino no se introdujo aisladamente en vasco. Si se compara la EMVA vasca con la EMVA tardo-latina correspondiente, se puede comprobar que son análogas, ya que ambas están formadas por el verbo principal en participio más el verbo auxiliar conjugado, habeo en latín y su equivalente ukan en vasco. Además, ambos verbos están en la misma posición, ya que el verbo principal precede al verbo auxiliar, y significan lo mismo, ya que ambas EMVAs corresponden al pretérito perfecto cuando el verbo auxiliar está en presente, y al pretérito pluscuamperfecto cuando el verbo auxiliar está en pasado. Así, por ejemplo, la EMVA transitiva vasca $a d i t u d u t$ = 'yo lo/la he oído' es análoga a la EMVA 
transitiva tardo-latina *auditu habeo = 'yo he oído', ya que ambas están formadas por el verbo principal en participio (aditu en vasco y *auditu $<$ auditum en latín) seguido del verbo auxiliar en presente de indicativo ( $d u t$ en vasco y habeo en latín). De la misma manera, la EMVA intransitiva vasca sortu naiz = 'yo he nacido' es análoga a la EMVA transitiva tardolatina *ortu sum = 'yo he nacido', ya que ambas están formadas por el verbo principal en participio (sortu en vasco y *ortu < ortum en latín) seguido del verbo auxiliar en presente de indicativo (naiz en vasco y sum en latín). Sin embargo, y curiosamente, al ser orior un verbo deponente, el pretérito perfecto tenía EMVA ya en latín clásico y se formaba con el participio pasado seguido del verbo auxiliar intransitivo sum en presente de indicativo, ortus sum = 'yo he nacido' = 'yo soy nacido', por lo que la EMVA intransitiva vasca sortu naiz = 'yo he nacido' = 'yo soy nacido' es análoga a la EMVA del latín clásico. Lo mismo ocurre con la EMVA vasca del pretérito pluscuamperfecto, tanto la transitiva como la intransitiva. Así, aditu nuan = 'yo (lo/la) había oído' es análoga a la EMVA transitiva tardo-latina del pretérito pluscuamperfecto, *auditu habebam = 'yo había oído', ya que ambas están formadas por el verbo principal en participio seguido del verbo auxiliar en pretérito imperfecto de indicativo. Igualmente, sortu nintzan = 'yo había nacido' = 'yo era nacido' es análoga a la EMVA intransitiva tardo-latina *ortu eram = "yo había nacido', e incluso a la EMVA pasiva ortus eram = 'yo había nacido' = 'yo era nacido' del verbo deponente orior = 'nacer, salir' del latín clásico.

Esta analogía entre las EMVAs del pretérito perfecto y del pretérito pluscuamperfecto del vasco y del latín tardío nos está indicando que el participio latino auditu $(m)$ no se introdujo aisladamente en vasco, sino formando parte del SMV del pretérito perfecto, mientras que el verbo auxiliar latino habeo = 'tener' se sustituyó por el verbo vasco de significado equivalente, esto es, ukan = 'tener'. Tanto el verbo latino habeo como el verbo vasco ukan significaban originalmente solo 'tener', y fue solo al haberse convertido en verbos auxiliares, cuando se traducen también por 'haber'. Entonces, se sustituyeron en algunas lenguas por otros verbos distintos: por el verbo latino tenere = 'sostener' en las lenguas romances de la Península Ibérica y por el verbo $e d u k i$ en vasco, que era el derivado trivalente de $u k a n$, formado por el radical $e d u$ - más el sufijo indicador de dativo - $k i$. Este proceso también fue análogo en ambas lenguas.

Para formar los demás modos de la EMVA vasca, no hubo más que sustituir la EMVS del verbo auxiliar transitivo ukan o del intransitivo izan por la EMVS de los demás modos de esos mismos verbos auxiliares. Por ejemplo, aditu duket = 'yo lo/la podré oír' = 'yo lo/la oiré', aditu nuke = 'yo lo/la podía oír' = 'yo lo/la oiría', aditu banu = 'si yo lo/la oyera', etc. Sin embargo, las EMVAs de los demás modos verbales vascos ya no se formaron por analogía con el latín, sino que siguieron un procedimiento 
distinto y propiamente vasco, es decir, sustituyendo el SMV de los verbos auxiliares (dut por duket, nuen por nuke, banu, etc., por ejemplo). Así se explica la aparición de la EMVA vasca.

Pero esta EMVA vasca, aparecida por imitación de la EMVA tardolatina, no solo se utilizó con los verbos de origen latino que se introdujeron en vasco, sino que se generalizó después a los verbos patrimoniales, que hasta entonces solo tenían EMVS sintética. La EMVA, por tanto, además de permitir conjugar los verbos de origen latino que se introdujeron en vasco, también permitió convertir en verbos muchas palabras vascas que no lo eran (sustantivos, adjetivos, adverbios, etc.), añadiéndoles simplemente el sufijo $-t u>-d u$. Por ejemplo, del adjetivo-adverbio hurbil = 'cerca', se formó el verbo hurbil-du = 'acercar, acercarse'; del adjetivo numeral $b a t=$ 'uno', se formó el verbo *bat-tu > ba-tu= 'unir', etc.). Pero no solo eso. La EMVA permitió, además, que los verbos patrimoniales pudieran expresar el aspecto perfecto y el imperfecto, que por tanto tienen también origen latino. Eso explica que el aspecto perfecto solo se puede expresar en vasco mediante la EMVA analítica, y no mediante la EMVS sintética. Después aparecieron en vasco otros dos aspectos, el habitual y el continuo, siguiendo el modelo establecido en el perfecto y el imperfecto.

No termina aquí la influencia de la EMVA tardo-latina en la EMVA vasca, ni los parecidos entre las EMVA de ambas lenguas, sino que también alcanza al tipo de verbo auxiliar utilizado con cada verbo principal. En la EMVA vasca del modo indicativo, si el verbo principal es transitivo, el verbo auxiliar que lo acompaña también lo es ( ukan = 'haber, tener'), pero si el verbo principal es intransitivo, el verbo auxiliar que lo acompaña es igualmente intransitivo (izan = 'ser'). Esto es, precisamente, lo mismo que ocurre en la EMVA tardo-latina y romance. Además, el verbo auxiliar transitivo $u k a n$ = 'haber, tener' y el verbo auxiliar intransitivo $i z a n=$ 'ser' son los equivalentes en vasco a los verbos auxiliares tardolatinos, al transitivo habere = 'haber, tener' y al intransitivo esse = 'ser', respectivamente. Ya se han citado como ejemplos el transitivo aditu $d u t=$ 'yo lo/la he oído' y el intransitivo sortu naiz = 'yo he nacido', análogos ambos a los tardo-latinos $\operatorname{auditu}(\mathrm{m})$ habeo = 'yo he oído' y ortu $(\mathrm{m})$ sum = 'yo he nacido' o sortu $(m)$ sum = 'yo he surgido'. Por lo tanto, el origen tardo-latino de la EMVA vasca abarcó todas las características de la EMVA tardo-latina original que le sirvió de modelo.

Tomando como ejemplo las EMVA de los dos verbos mencionados, el transitivo aditu = 'oír' y el intransitivo sortu = 'nacer', se puede ver claramente el origen tardo-latino de sus EMVA respectivas: nik aditu $d u t=$ 'yo lo/la he oído'; nik aditu nuen = 'yo lo/la había oído'; ni sortu naiz = 'yo he nacido'; ni sortu nintzen = 'yo había nacido'. Sin embargo, estos dos SMVA de sortu utilizan el verbo intransitivo izan = 'ser' como verbo auxiliar, por lo que su traducción literal es la misma que la del 
francés y el italiano, y también es la misma que la del castellano antiguo. Es típica la expresión del Poema de Mio Cid: que en buena ora fostes nado 'que en buena hora fuiste nacido' = 'que en buena hora naciste'. Por lo tanto, los dos SMVA de sortu intransitivos anteriores se pueden traducir también con el verbo auxiliar intransitivo ser: ni sortu naiz = 'yo soy nacido'; ni sortu nintzen = "yo era nacido" ${ }^{14}$.

La voz pasiva vasca actual también es análoga a la voz pasiva tardolatina o romance, formada por el verbo principal en participio pasado más el verbo auxiliar intransitivo conjugado, con la única particularidad de que en vasco se le añade el artículo enclítico - $a$ al verbo principal. Por eso, la voz pasiva vasca carece de EMVS sintética y solo posee EMVA analítica, que se formó mediante la imitación exacta de su correspondiente tardo-latina o romance y con la única particularidad de que se le añadió el artículo enclítico al verbo principal para diferenciarla de la activa. Así, por ejemplo, aditu-a naiz = 'yo soy oído' es análogo a audi$t u(m)$ sum = 'yo soy oído' del latín tardío, aditu- $a$ nintzen = 'yo era oído' es análogo al tardo-latino $\operatorname{auditu}(\mathrm{m})$ eram = 'yo era oído', y así sucesivamente con todos los tiempos ${ }^{15}$. Como es sabido, auditu $(m)$ sum = 'yo soy oído' sustituyó en el latín tardío a audior = 'yo soy oído’ del latín clásico, $\operatorname{auditu}(\mathrm{m})$ eram = 'yo era oído’ a audiēbar = 'yo era oído', etc., lo que quiere decir que la voz pasiva analítica vasca apareció por analogía con la voz pasiva tardo-latina o romance cuando esta ya se había formado, o sea, en la Alta Edad Media, que es precisamente la época en la que apa-

14 Como el verbo vasco sortu se explica por la combinación de los participios del latín vulgar de los verbos orior = 'nacer' y surgo = 'levantarse, surgir' (ortu< ortum y *sortu< *surctum, respectivamente), la comparación hay que hacerla con los correspondientes SMVA de estos dos verbos latinos, teniendo en cuenta que estos participios se introdujeron en vasco en un momento muy concreto de su evolución fonética, cuando el nominativo *sŭrctus se había sustituido por su acusativo *sŭrctum y este había evolucionado a sortu mediante el cambio fonético $k>\varnothing$, el cambio fonético $-m>\emptyset$ y el cambio fonético $\breve{u}>o$, pero antes de que el participio *sŭrctus del latín vulgar fuera sustituido por el nuevo participio *surgitum regular con el infinitivo y los tiempos del infectum: por ejemplo, el vasco sortu naiz = 'yo he nacido' procede del latín $\operatorname{ortu}(\mathrm{m})$ sum = 'yo he nacido' y de $\operatorname{sortu}(\mathrm{m})$ sum = 'yo me he levantado', y el vasco sortu nintzen = 'yo había nacido' procede del latín $\operatorname{ortu}(\mathrm{m})$ eram = 'yo había nacido' y de $\operatorname{sortu}(\mathrm{m})$ eram = 'yo me había levantado'.

${ }^{15}$ Laffitte 1962 [1944], p. 342 pone como ejemplo Paulo maitatua da = 'Paul est aimé' o Sagarrak bilduak dira = 'les pommes sont cueilles'. El sujeto paciente se expresó mediante el caso nominativo, igual que el objeto directo de la voz activa, y el complemento agente mediante el ergativo, igual que el sujeto agente de la voz activa, de manera que los casos que intervienen en la pasiva son los mismos que los de la activa pero en orden inverso. Rebuschi 1977, p. 79 pone un ejemplo muy ilustrativo: txakurrek Peio ausiki dute significa «les chiens ont mordu Peio (processus achevé)» con el verbo principal en Participio indeterminado (ausiki); si se emplea el participio determinado (ausiki-a / ausiki-rik / ausiki-ta), la frase txakurrek Peio ausikia dute/daukate significaría literalmente «los perros tienen mordido a Peio» («état resultant»); y la pasiva correspondiente es Peio txakurrek ausikia da/dago «Peio a été mordu par les chiens», literalmente «Peio es mordido por los perros» o «Peio está mordido por los perros», según se utilice el verbo izan 'ser' o egon 'estar'. 
reció en vasco el artículo enclítico por analogía con el artículo del latín tardío y el romance, que procede del demostrativo ${ }^{16}$. La EMVA pasiva vasca, introducida por analogía con la EMVA pasiva tardo-latina, también se utiliza en vasco como un medio de reducción de valencias, igual que en latín y en las lenguas románicas. Lo que ocurre en realidad es que la voz pasiva convierte a los verbos transitivos en intransitivos, con lo cual los SMVA transitivos pasivos, como el de aditu = 'oír' son equivalentes a los SMVA(N) intransitivos como el de sortu = 'nacer'.

La EMVA latina tiene su origen en época muy temprana. La EMVA intransitiva, con el verbo esse = 'ser', existía ya en los verbos deponentes desde época muy antigua y la EMVA transitiva con el verbo habere = 'tener' ya se documenta en época clásica (Salustio, Tito Livio, Cicerón, Catón el Viejo) con el significado de 'tener' o 'poseer' más el participio, ya que ese era el significado del verbo latino habère. Así, por ejemplo, habeo scriptum no significaba exactamente «he escrito», sino más bien «tengo escrito», pero habes cognitum significaba tanto «tienes conocido» como «has conocido», e invitatum habes podía significar lo mismo «tienes invitado» como «has invitado». Por lo tanto, la perífrasis latina formada por un participio pasado más el verbo habère expresaba originalmente la idea de resultado de una acción anterior y después tomó el valor temporal de anterioridad, pasando a expresar acciones previas al momento del habla o, más exactamente, la acción que había tenido un desarrollo previo pero cuyos resultados llegan hasta el presente (Egido 1996, p. 239). Tuvo su origen en el latín arcaico, se documenta en el latín clásico y es mucho más frecuente en los textos de la Galia merovingia ${ }^{17}$, aun-

${ }^{16}$ El origen latino o romance de la EMVA vasca es aceptado actualmente de forma general: «Contact, first with Latin and then with the Romance languages, must have at least promoted and accelerated the rapid development and expansion of the system of periphrastic forms, if it did not in fact give rise to it» (Gómez y Sainz 1995, p. 238). L. Michelena 1987a, p. 48 advirtió el paralelismo morfológico entre la EMVA vasca y la de otras lenguas europeas occidentales $($ ej.: etorri $d a=$ cast. ant. es venido $=$ fr. est venu $=$ al. ist gekommen; egin $d u=$ cast. ha hecho $=$ fr. $a$ fait $=$ hat gemacht; joango $d a=$ cast. ant. es de ir, egingo $d u=$ cast. ant. ha de hacer $)$.

17 El origen de la construcción viene de lejos, pues habeo acompañado de un participio existía ya en época clásica. En ese momento, sin embargo, los dos componentes tenían su función semántica bien diferenciada: habeo marcaba la acción de 'poseer', de 'tener', de 'tener bajo la dependencia de uno', etc., mientras que el participio se refería a una acción cumplida por la persona que designaba el sujeto, como ocurre, por ejemplo, en Tito Livio, 22, 4, 5 ubi clausum lacu ac montibus et circumfusum suis copiis habuit hostem, 'cuando tuvo ya al enemigo encerrado entre el lago y las montañas y rodeado por sus propias tropas'. En los casos en que el participio designaba una acción del espíritu más que una modificación sensible y material, la expresión no evocaba ya dos movimientos distintos y la unidad de los dos componentes era más estrecha como, por ejemplo, en Cicerón, Epistulae ad familiares, 13, 17, 3 sin autem ... nondum eum satis habes cognitum, 'pero si no ... lo has conocido (= tienes conocido) todavía suficientemente' (la expresión es paralela a la inmediatamente anterior de 13, 17, 2 quem si tu iam ... cognosti). Las cosas permanecieron así mucho tiempo, la perífrasis era de uso escaso y no estaba ni fijada ni gramaticalizada. Solo en la latinidad de la segunda mitad del primer milenio los ejemplos se vuelven más frecuentes y desbordan los límites del viejo tipo cognitum habere, 
que en el habla popular se generalizaría mucho antes como suele ocurrir $^{18}$. Como es normal, los textos escritos, y sobre todo los literarios, son mucho más conservadores que el lenguaje popular por lo que, cuando un fenómeno lingüístico se refleja en la literatura es normalmente porque está plenamente consolidado en el habla coloquial. Por ello, se puede hablar del origen de esta EMVA latina en el latín vulgar de la época clásica y de su plena consolidación en la época merovingia.

M. Alvar y B. Pottier 1983, p. 156 también mantienen que los perfectos con habere en los verbos transitivos y esse en los intransitivos se inician en la Galia en el siglo IV y se generalizan en el siglo VI en otras partes del Imperio. El paso de la antigua perífrasis al pretérito perfecto fue lento, ya que aún no estaba consumado en el castellano de la Edad Media, en el que la EMVS del pretérito indefinido y la EMVA del pretérito perfecto conservan los significados originarios junto a los nuevos. Así, por ejemplo, amé significaba tanto 'amé' como 'he amado', igual que el $a m \bar{a} v \bar{\imath}$ latino del que procede (amāvi >amai > amé), y he amado significaba tanto 'he amado' como el original 'tengo amado'. En los documentos leoneses, la EMVA del pretérito perfecto tiene un uso muy escaso y expresa mayoritariamente el resultado de una actividad previa, es decir, mantiene el valor originario de la perífrasis románica 'ten-

compertum habere; cuando leemos por ejemplo, en Gregorio de Tours, Historia Francorum, V, 25 Scis enim quod foedus inter nos initum habemus, uno siente la tentación de traducir por un simple pasado: 'sabes, pues, que hemos concluido un pacto entre nosotros', aunque en sentido estricto pueda seguir dándose a habemus su significado propio de 'tener', 'disponer de' ('tenemos un pacto concluido'). Pero la unidad de los dos miembros de la perífrasis no plantea, en cambio, ninguna duda en una frase como Ecce episcopum ... inuitatum habes, et uix nobis supersunt quattuor uini amphorae (Gregorio de Tours, Vitae patrum, III, p. 1), 'hete aquí que has invitado al obispo ... y apenas nos quedan cuatro ánforas de vino'. En esta época, de todos modos, la construcción no es ni constante ni sistemática, y en este sentido habría que observar también que el orden de los elementos es inverso al orden en las lenguas románicas (donde se encuentra casi siempre desde el principio habere + participio). En cualquier caso, es más que probable que, en la lengua hablada de la época, la formación de un sistema de tiempos compuestos estuviese más avanzada de lo que se podría pensar por los documentos escritos. Es destacable, en efecto, que la mayor parte de los ejemplos que se documentan en Gregorio de Tours se encuentran en el discurso directo, en los pasajes donde el autor reproduce palabras de los personajes (Herman 1997, pp. 92-93).

${ }_{18}$ Ya en latín clásico se pueden encontrar significados muy cercanos al perfecto para esta perífrasis: compertum ego habeo (Salustio), satis habeo deliberatum (Cicerón), dicam de istis Graecis ..., quid Athenis exquisitum habeam (Catón el Viejo). Quizás sea Cicerón el autor clásico que más la cultive. Herzog cree que en el lenguaje popular se convertiría en perfecto en la primera parte del siglo I d. C. pero los escritores la evitan a partir de esa fecha hasta el siglo VI en que reaparece [...] Esta nueva perífrasis que triunfa a partir del siglo vi se diferencia de la antigua, según Thielmann, en que en esta segunda fase de la perífrasis habere amplía sus posibilidades combinatorias para crear perífrasis con más participios, mientras que en el período clásico solo era común su uso en un número limitado de casos. En la perífrasis antigua, habe$r e$ seguía manteniendo su independencia respecto al participio, mientras que en las nuevas formaciones habere va perdiendo su autonomía de significado, para convertirse, cada vez más claramente, en auxiliar del pretérito perfecto (Egido 1996, p. 35). 
go + participio pasado', de manera que he amado significa mayoritariamente 'tengo amado' (Egido 1996, p. 239). En la EMVA vasca se puede observar que los dos verbos que la forman, el principal y el auxiliar, conservan el mismo orden que tenían en latín vulgar y en latín tardío, ya que el participio precede al verbo auxiliar.

El significado originario de la EMVA transitiva románica con habēre = 'tener, poseer' del pretérito perfecto explica la utilización de otro verbo auxiliar distinto, el intransitivo esse = 'ser', en la EMVA intransitiva de ese mismo tiempo verbal, ya que esta última no tendría sentido con el verbo transitivo habere con su significado originario de «tener, poseer». En efecto, *venitus habeo por ejemplo, sería incorrecta porque no podía significar «tengo venido", ya que habeo = 'tengo' es un verbo transitivo y venitus = 'venido' no lo es. Pero esa misma perífrasis sí que tiene sentido, en cambio, con el verbo intransitivo esse = 'ser', esto es, venitus sum = 'yo soy venido', ya que ambos verbos son intransitivos. En la EMVA vasca ocurre lo mismo, ya que ukan también significa «tener» y todavía conserva este significado cuando no forma parte de la EMVA. Por eso, una expresión como *etorri dut, por ejemplo, es incorrecta porque no puede significar 'tengo venido', ya que $d u t=$ 'tengo' es un verbo transitivo y etorri = 'venido' no lo es. En cambio, esa misma perífrasis sí que tiene sentido con el verbo intransitivo izan = 'ser', esto es, etorri naiz = 'yo soy venido', ya que ambos verbos son intransitivos.

Estos dos verbos vascos, ukan e izan, tuvieron que ser originalmente los únicos verbos auxiliares de la EMVA vasca, igual que ocurría en el latín tardío y en todas las lenguas románicas durante la Edad Media y tal como se han conservado actualmente en francés y en italiano, esto es, avoir = 'haber' con los verbos transitivos y être = 'ser, estar' con los intransitivos en francés (por ejemplo, il a dit = 'él ha dicho', pero il est venu $=$ 'él ha venido'), avere $=$ 'haber' con los verbos transitivos y essere $=$ 'ser, estar' con los intransitivos en italiano (por ejemplo, egli ha detto = 'él ha dicho', pero egli è venuto = 'él ha venido'). Sin embargo, en la EMVA de las lenguas románicas de la Península Ibérica se utilizó el verbo auxiliar transitivo haber también con los verbos intransitivos, generalizándose así el mismo verbo haber para todos los verbos, tanto transitivos como intransitivos. En la EMVA vasca, por el contrario, no solo se siguieron utilizando los dos verbos auxiliares originales ukan e izan, sino que además aparecieron después otros verbos auxiliares para diferenciar las flexiones de $33^{\mathrm{a}}$ persona de algunas EMVAs y algunos tiempos y modos verbales concretos dentro de la EMVA general.

La EMVA vasca sirvió para expresar los modos verbales nuevos que no existían en vasco (subjuntivo, potencial y la $2^{\underline{a}}$ persona del imperativo), pero entonces surgió un problema: en vasco solo existían dos tiempos y dos modos que pudieran ser utilizados en el verbo auxiliar, el presente y el pasado de indicativo, y el potencial/condicional. La for- 
mación de la EMVA del futuro y del condicional utilizó el presente y el pasado del modo condicional en el verbo auxiliar, pero la formación de una EMVA de subjuntivo y de potencial diferente de la EMVA del futuro y del condicional fue un problema, ya que en subjuntivo se utilizaban las mismas EMVS que en indicativo, y en futuro y condicional, las mismas EMVS que en presente y en pasado de potencial. El imperativo, por su parte, se confundía con el pasado en las flexiones de la $3^{\underline{a}}$ persona; en $1^{\underline{a}}$ y $2^{\underline{a}}$ persona utilizó después el presente de subjuntivo por analogía con las lenguas romances. Los modos y tiempos verbales que se confundían eran los siguientes:

- El futuro y el condicional se confundían con el presente y el pasado de potencial, respectivamente, debido a que ni el futuro ni el condicional existían como tiempos verbales con una EMVS propia, sino que se expresaban mediante la misma EMVS que el presente y el pasado del modo potencial respectivamente, es decir, con el sufijo de potencial -ke. Al utilizar ambos tiempos verbales las mismas EMV que el modo potencial, se confundían esos tiempos.

- El pasado de indicativo se confundía con el pasado de subjuntivo, debido a que en ambos se utilizaba la misma EMVS con sufijo -an/-en.

- El imperativo se confundía con el pasado de indicativo en las flexiones de 3 a persona antes de que en la EMVS el pasado de indicativo se añadiera el sufijo de pasado -an/-en.

La diferenciación de las EMVA se solucionó de la única manera posible, es decir, sustituyendo los verbos auxiliares ukan e izan por otros distintos en los modos subjuntivo y potencial ( izan = 'ser' y egin = 'hacer' con los verbos transitivos y ekin = 'inculcar, insistir' con los intransitivos). Por ejemplo, etor dakizun = 'para que vos vengáis' o ekar dezazun / ekar dagizun = 'para que vos lo/la traigáis' frente al indicativo relativo etorri den = 'que ha venido' y datorren = 'que viene' o ekarri duen = 'que lo/la ha traído' y dakarren = 'que lo/la trae'. La EMVA de imperativo utilizó la EMVA del presente de subjuntivo, igual que en las lenguas romances, pero las flexiones de $33^{\text {a }}$ persona de ergativo (E) o de dativo (D) conservaron la antigua EMV del imperativo. Por ejemplo, $b-e-z a=$ 'hayalo él/ella/ello' o $e-z a-z u=$ 'habedlo vos', pertenecen al SMV antiguo del imperativo, pero $n-a-z a=$ 'hayame él/ella/ello' o $n-a-z a-z u=$ 'habedme vos', proceden del presente de sujuntivo sin la conjunción enclítica (-en,-ela).

Por lo tanto, en los modos imperativo, subjuntivo y potencial se utilizaron otros verbos auxiliares que sustituyeron a los originales ukan e izan para diferenciarlos del modo indicativo y del condicional. Esos 
verbos fueron distintos en cada tipo de EMVS $^{19}$, en los distintos dialectos y en los distintos períodos históricos. Así, en la EMVA(N) unicasual intransitiva (nor), el verbo auxiliar intransitivo izan = 'ser' se sustituyó en esos tres modos verbales por el verbo $e$ din = 'coger' ${ }^{20}$. En las EMVA transitivas, tanto la bicasual como la tricasual, se utilizó el verbo $i z a n=$ 'ser', pero como verbo transitivo, y en vizcaíno se sustituyó posteriormente por egin = 'hacer' ${ }^{21}$. En la EMVA bicasual intransitiva,

19 Para simplificar, expresamos los distintos tipos de EMVS de forma simbólica según los casos que tienen. Así, a la estructura unicasual (nor) la denominaremos EMV(N) porque solo tiene un caso, el nominativo $(\mathrm{N})$; a la estructura bicasual transitiva (nor-nork), que tiene dos casos, el nominativo (N) y el ergativo (E), la denominaremos EMV(NE); a la estructura bicasual intransitiva (nor-nori), cuyos dos casos son el nominativo (N) y el dativo (D), la denominaremos EMV(ND); y a la estructura tricasual (nor-nori-nork), que tiene tres casos, el nominativo (N), el dativo (D) y el ergativo (E), la denominaremos EMV(NDE) (vid. Domene 2007a, II parte).

${ }^{20}$ Para diferenciarse de la EMVS(NE) bicasual transitiva de edin, a esa EMVS(N, edin) unicasual intransitiva se le añadió el sufijo - te, propio del futuro y del condicional del verbo izan (y antiguamente del modo potencial de dicho verbo), aunque en una parte del vizcaíno se ha conservado la EMVS(N, edin) sin sufijo - te. En imperativo, el sufijo - te del antiguo potencial se ha añadido solo en las personas de plural. Así, $n$ - $a$ - $d i-n=$ 'sea yo', $h$ - $a$-di = 'seas tú' y $b-e-d i=$ 'sea él/ella/ello' carecen del sufijo - $t$, pero g-a-i-te-z-en = 'seamos nosotros' (lit. 'podamos ser nosotros'), $z-a-i-t e-z=$ 'seáis vos' (lit. 'podáis ser vos'), $z$-a-i-te-z-te = 'seáis vosotros' (lit. 'podáis ser vosotros') y $b$-i-te-z = 'sean ellos' (lit. 'puedan ser ellos') sí que lo llevan (vid. Domene 2007a, II parte y Anexo II). El sufijo -te es propio del tiempo futuro (Azkue 1923-1925, II, p. 585), aunque solo se usa con los dos verbos auxiliares intransitivos izan y edin de la EMVA(N) unicasual. Se tuvo que utilizar antiguamente en todos los dialectos en las EMVS de los dos verbos y en la EMVS(edin) se usa todavía en la mayoría de ellos, pero en la EMVS(izan) solo se ha conservado en suletino ( heldu d-a-te = 'será', egon-en d-i-ra-te = 'estarán', etc.), si bien «en el siglo XVI estaba todavía en uso esta característica en el dialecto B. El núm. 173 de Refranes y Sentencias dice ezaun adi ta AIZATE ondo bizi 'conócete y serás de bien vivir (vivirás bien)'» (Azkue 1923-1925, II, p. 585). Por lo tanto, el SMV(N, edin) con sufijo de futuro -te del presente de subjuntivo es en realidad el antiguo $\operatorname{SMV}(\mathrm{N}$, edin) con sufijo de futuro -te del futuro que ha sustituido al antiguo $\operatorname{SMV}(\mathrm{N}$, edin) sin sufijo - te, que solo se ha conservado en vizcaíno. En las palabras de más de dos sílabas, la /d/ intervocálica de la raíz - $d i$ - ha desaparecido por el cambio fonético $d>\emptyset$. Por ejemplo, $n-a-d i-n=$ 'para que yo sea', pero $g$ - $a$ - $i$-z-an = 'para que nosotros seamos', $n-a-i-t e-n=$ 'para que yo sea', o $g-a-i$-te-z-an = 'para que nosotros seamos'. Al igualarse el SMV $(\mathrm{N}$, edin $)$ del presente de subjuntivo al antiguo SMV $(\mathrm{N}, e d i n)$ del futuro con sufijo -te, el $\operatorname{SMV}(\mathrm{N}$, edin) del futuro añadió el sufijo de potencial - $k e$ propio de los demás verbos, utilizándose así los dos sufijos de futuro, el sufijo - te propio de izan y edin y el sufijo de potencial -ke propio de todos los demás verbos. Por ejemplo, $n-a-i-t e-k e-n=$ 'para que yo sea' (vid. Domene 2007a, 2aㅡ parte y Anexo II).

${ }^{21}$ En las EMVA transitivas, es decir, la EMVA(NE) bicasual (nor-nork) y la EMVA(NDE) tricasual (nor-nori-nork), el verbo auxiliar transitivo ukan = 'haber, tener' se sustituyó por el intransitivo izan = 'ser'. Sin embargo, el verbo izan se utilizó como transitivo y, por ello, en las flexiones de plural se le añadió el sufijo de plural -it-, que era el propio del verbo auxiliar sustituido (ukan) (vid. Domene 2007b). Por ejemplo, nik aditu $d-u-t=$ 'yo lo/la he oído' en presente de indicativo y nik adi d-e-za-da-n= 'para que yo lo/la haya oído' en presente de subjuntivo, en singular de nominativo $(\mathrm{N})$, y nik aditu d-it-u-t = 'yo los/las he oído' en presente de indicativo y nik adi d-it-za-da-n = 'para que yo los/las haya oído' en presente de subjuntivo, en plural de nominativo (N). En vizcaíno, sin embargo, se utilizó el verbo transitivo egin = 'hacer' sustituyendo a $i z a n$ en los modos imperativo, subjuntivo y potencial. En vizcaíno, por ejemplo, nik aditu $d-o-t=$ 'yo lo/la he oído' en presente de indicativo y nik adi $d-a-g i-d a-n=$ "para que yo lo/la haya 
se utilizó ekin = 'ocuparse, inculcar, insistir' como verbo auxiliar en los modos imperativo, subjuntivo y potencial ${ }^{22}$.

La nueva EMVA, aparecida en vasco por imitación de la EMVA tardolatina, expresaba solo el aspecto perfecto, igual que en latín tardío, ya que el aspecto imperfecto se expresaba por medio de la EMVS en la lengua de Roma (audiēbam = 'yo oía', por ejemplo). Así, aditu dut = 'yo lo/la he oído' y aditu nuen = 'yo lo/la había oído' solo expresaban el aspecto perfecto y el pluscuamperfecto del pretérito respectivamente, lo mismo que en latín tardío auditu $(m)$ habeo = 'yo he oído' y auditu $(m)$ habebam = ‘yo había oído’ respectivamente, pero no podían expresar el aspecto imperfecto ni el puntual, que eran expresados por la EMVS en los verbos autóctonos. Por otro lado, los verbos de procedencia latina o roman-

oído' en presente de subjuntivo, en singular de nominativo $(\mathrm{N})$, y nik aditu d-o-da-z = 'yo los/las he oído' (presente de indicativo) y nik adi $d$-a-i-da-z-ala = 'que yo los/las haya oído' (presente de subjuntivo), en plural de nominativo (N). El verbo auxiliar de la EMVA(NDE) tricasual de los modos indicativo y condicional fue sustituido por iraun = 'durar' en todos los dialectos, pero solo en las flexiones de $3^{-\underline{a}}$ persona de dativo, para diferenciarse de las flexiones de $3^{\underline{a}}$ persona de nominativo. Por ejemplo, $d$-a-o $(<d$-a-ro $<d$-a-rau $), d$-e-ro $(<d$-e-rau $)=$ '(él/ella/ello) se lo/la ha (a él/ella/ello)'; pero $d-a-\hat{u}(<d-a-g u<d-a$-u-gu), $d$-e-gu = '(él/ella/ello) nos lo/la ha'. En época más moderna, el verbo auxiliar ukan/iraun fue sustituido en todas las personas por el verbo transitivo eutsi = 'asir, agarrar, sostener' en vizcaíno (por ejemplo, $d$-e-uts-a-t = '(él/ella/ello) me lo/la ha') y por el verbo transitivo edin = 'coger' en alto-navarro y parte oriental del guipuzcoano (por ejemplo, $d-i-t<d-a-i-t<* d-a-d i-t=$ '(él/ella/ello) me lo/la ha') (vid. Domene 2008a; 2007e; 2007a, Anexos III y V al XII).

${ }^{22}$ En las EMVA(ND) bicasuales intransitivas (nor-nori), el verbo auxiliar intransitivo $i z a n=$ 'ser' se sustituyó por el verbo ekin = 'ocuparse, inculcar, insistir' en los modos imperativo, subjuntivo y potencial y en las flexiones de $3^{\underline{a}}$ persona de nominativo de todos los dialectos. Por ejemplo, hura etorri d $a=$ 'él/ella/ello ha venido', pero hura etorri $z-a-k-o=$ 'él/ella/ello le ha venido (a él/ella/ello)' y ni etorri n-a-it-za-ki-o = 'yo le he venido (a él/ella/ello)' en presente de indicativo y ni etorri $n-a-k i$-o = 'para que yo le haya venido (a él/ella/ello)' en presente de subjuntivo. En parte del vizcaíno, también se produjo esa sustitución en todas las personas de los modos indicativo y condicional. El verbo auxiliar de la EMVA(ND) de los modos indicativo y condicional también fue sustituido, en época más moderna, por el verbo auxiliar transitivo de la EMVA(NDE) tricasual de cada dialecto, es decir, por el verbo transitivo ukan/iraun en bajonavarro, suletino y roncalés -por ejemplo, $z-a-u-t=$ '(él/ella/ello) me es' procede de $d-a-u-t=$ '(él/ella/ello) me lo/la ha'-, y por el verbo transitivo edin = 'coger' en las flexiones de $3^{\underline{a}}$ persona de nominativo en alto-navarro septentrional y en la parte oriental del guipuzcoano -por ejemplo, $z-a-i-t=$ ' (él/ella/ello) me es' procede de $d-a-i-t>d-i-t=$ '(él/ella/ello) me lo/la ha'-, y más tarde en todas las personas del alto-navarro meridional -por ejemplo, $g$ - $a-i-z k i-o=$ 'nosotros le somos (a él/ella/ello)'-. En parte del vizcaíno, el verbo auxiliar izan = 'ser' de los modos indicativo y condicional se sustituyó por el verbo ekin = 'inculcar, insistir' en todas las flexiones de la EMVA. Por ejemplo, ni etorri naiz = 'yo he venido' pero 'yo le he venido (a él/ella/ello)' es $n i$ etorri $n$ - $a$-ki-o en vizcaíno occidental y ni etorri $n$-a-it-za-ki-o en los demás dialectos. Al igualarse de nuevo el modo indicativo con el subjuntivo, el primero se tuvo que volver a diferenciar, pero de otra manera, añadiendo en el sufijo indicador de alocutivo $-i$ - y reduplicando el sufijo de tiempo. Por ejemplo, ni etorri $n-a-i-a-k-0=$ 'yo le he venido (a él/ella/ello)' en presente de indicativo y ni etorri $n-a-k i-o$ = 'para que yo le haya venido (a él/ella/ello)' en presente de subjuntivo. El nuevo SMVS(ND, ekin) del indicativo con sufijo - $i$ - y reduplicación del sufijo de tiempo ha sufrido una evolución fonética siguiendo las leyes fonéticas vascas (por ejemplo,

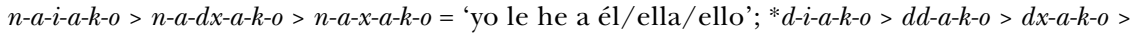
$x-a-k-o>j-a-k-o=$ 'él/ella/ello le ha a él/ella/ello') (vid. Domene 2007a, Anexo IV). 
ce carecían de EMVS vasca y, por tanto, no podían expresar el aspecto imperfecto ni el puntual. Para conseguirlo, fue necesario realizar algunos ajustes en la EMVA vasca, que consistieron en la utilización del verbo principal en gerundio, en vez de en participio, o en la utilización del mismo verbo principal como verbo auxiliar. La utilización del verbo principal en gerundio consistió en la adición del sufijo verbal -te-n/-tze-n al radical del verbo principal, no a su participio (a etor-, no a etorri; a ekar-, no a ekarri, a adi-, no a aditu, etc.). Las dos EMVA surgidas de estos dos procedimientos dieron lugar a los otros dos aspectos verbales vascos: el habitual, que tiene el verbo principal en gerundio, y el continuo, que utiliza el mismo verbo principal como verbo auxiliar ${ }^{23}$. El aspecto puntual o imperfecto, en cambio, se seguía expresando mediante la EMVS: por ejemplo, ni nabil = 'yo ando' es el aspecto puntual, ni ibil-tzen naiz= 'yo suelo andar', el aspecto habitual y ni ibil-i nabil = 'yo estoy andando' (lit. 'yo ando andando'), el aspecto continuo. Puesto que en la EMVA el aspecto habitual se indica con el verbo principal en gerundio, no se podía expresar el presente puntual de los verbos nuevos, porque carecían de EMVS. Por ello, hubo que recurrir a un procedimiento más complejo todavía para poder expresar el presente puntual, que consistió en utilizar el verbo ari = ‘ocuparse, estar ocupado’ (Azkue 1905-1906, p. 64-65) como verbo modal con el verbo principal en gerundio con -ten/-tzen. Así, nik adi-tzen $d u t=$ 'yo lo/la suelo oír' es el presente habitual y ni adi-tzen ari naiz = 'yo lo/la oigo, me ocupo en oírlo/la', el presente puntual ${ }^{24}$.

Desde que la EMVA apareció en vasco, la tendencia ha sido la sustitución progresiva de la EMVS de todos los verbos por dicha EMVA, porque esta última solo necesita utilizar la EMVS de los verbos auxiliares. Por ello, las únicas EMVS que se han conservado en la actualidad son prácticamente las de dichos verbos auxiliares. Sin embargo, incluso en los verbos auxiliares se ha producido ese mismo fenómeno de sustitu-

\footnotetext{
${ }^{23}$ Por lo tanto, los verbos alóctonos, de procedencia latina o romance, solo expresaban el aspecto perfecto y el pluscuamperfecto del pretérito, pero no podían expresar el aspecto imperfecto o el aspecto puntual porque carecían de EMVS. Los verbos autóctonos vascos expresaban el aspecto puntual y el imperfecto por medio de la EMVS y en la EMVA lo tuvieron que expresar utilizando el mismo verbo principal como verbo auxiliar, lo que posteriormente dio lugar al aspecto continuo vasco. Los verbos alóctonos vascos, procedentes del latín o del romance, no pudieron utilizar el mismo verbo principal como auxiliar, porque carecían de EMVS, y por ello no tuvieron otro remedio que modificar el verbo principal, en vez del auxiliar, utilizándolo en gerundio en vez de en participio, lo que posteriormente dio lugar al aspecto habitual vasco. Los verbos autóctonos vascos también utilizaron después el verbo principal en gerundio, en vez de en participio, para expresar el aspecto habitual.

${ }^{24}$ Como el verbo ari = 'ocuparse, estar ocupado' es intransitivo, el verbo auxiliar que le acompaña es siempre $i z a n=$ 'ser', aunque el verbo al que acompaña ari sea transitivo: por ejemplo «bazkaltzen ari naiz, 'estoy comiendo, me ocupo en comer'» (Azkue 1923-1925, II, p. 527). El verbo ari es intransitivo y, por tanto, «el infinitivo se forma añadiéndole izan: ari izan, 'ocuparse'; ari da, 'se ocupa'; ari izaten da, 'suele ocuparse'; ari izango o izanen da, 'se ocupará'» (Azkue 1905-1906, I, p. 64).
} 
ción de la EMVS por la EMVA en algunos tiempos y modos verbales vascos, como el futuro y el condicional, si bien en época muy reciente. En ellos, las EMVS del verbo auxiliar de las antiguas EMVA de cada uno de esos dos tiempos (aditu duket = 'yo lo/la puedo oír, yo lo/la oiré' y aditu $n u k e=$ 'yo lo/la podía oír, yo lo/la oiría') se sustituyeron por las EMVS del presente y del pasado, añadiéndosele al verbo principal en participio el sufijo de genitivo, el sufijo $-k o$ en los dialectos meridionales y el sufijo -en en los septentrionales. Así, por ejemplo, ikusi duket = 'yo lo/la veré' se ha sustituido por $i k u s i-k o d u t=$ 'yo lo/la veré' en vizcaíno, guipuzcoano y alto-navarro, y por ikusi-ren dut = 'yo lo/la veré' en labortano, bajo-navarro, suletino y roncalés ${ }^{25}$.

Pero, si bien ikusi duket = 'yo lo/la veré', significa literalmente 'yo lo/la habré visto', tanto ikusi-ko dut = 'yo lo/la veré' como ikusi-ren $d u t=$ 'yo lo/la veré' son la traducción literal de la perífrasis de obligación castellana yo lo/la he de ver o de la catalana jo l'/ho he de veure. En efecto, $d$ - $u$ - $t$ significa 'yo lo/la he' o 'jo l' / ho he', los sufijos de genitivo -ko y -en son la traducción de la preposición románica 'de' y el verbo principal, ikusi, estaría entonces en infinitivo, y no en participio, porque sería la traducción literal del infinitivo románico ver o veure. Por lo tanto, es evidente que esta EMVA apareció por imitación de la perífrasis de obligación castellana y, por ello, el significado real de ikusi-ko dut y de ikusiren dut no es 'yo lo/la veré', sino 'yo lo/la he de ver', y así es como lo traduce Azkue 1923-1925, p. 530: ekarriko dut = 'yo lo/la he de traer'. Igualmente, ikusi-ko nuan e ikusi-ren nuen significan literalmente 'yo lo/la había de ver', y no 'yo lo/la vería'. La cronología reciente de esta EMVA vasca se refleja en su diversidad dialectal, ya que es diferente en los dialectos vasco-españoles y en los vasco-franceses, por lo que aparecería y se generalizaría cuando se interrumpió la relación entre los territorios de habla vasca de ambos lados de la frontera hispano-francesa.

Esta tendencia analítica y perifrástica ha sido general en la EMV vasca y, recientemente, se ha tendido a sustituir también la EMVA del modo potencial por la Estructura Sintáctica Verbal Perifrástica (ESVP) correspondiente, utilizando el verbo modal $a h a l=$ 'poder' cuando es afirmativo y ezin = 'no poder' cuando es negativo. Así, por ejemplo, ikusi dezaket = 'yo lo/la puedo ver' ha sido sustituido por ikusi ahal dut = 'yo lo/la puedo ver' y ez dezaket ikusi = 'yo no lo/la puedo ver' ha sido sustituido por ezin ikusi $d u t=$ 'yo no lo/la puedo ver'. También se ha sustituido la EMVA

25 «El futuro de un verbo, seguido de auxiliar, se indica modernamente con el sufijo en entre los orientales, con el sufijo ko en B y G: ikusiren dut, ikusiko dot o det lo he de ver. En AN se valen de en con verbos terminados en $n$ y $l$, con los demás hacen uso de ko: erranen dut lo diré, ilen da morirá, izain (contracción de izanen) dira han de ser, ekarriko dut lo traeré, yoko due lo pegarán ... etc. En Santa Engracia (S) se valen de los dos: erranenko düzüt lo diré (lit. os lo he de decir). Una y otra desinencia de futurición proceden de la declinación: en desinencia posesiva, ko proverbal» (Azkue 1923-1925, II, p. 528). 
del aspecto habitual por la ESVP del modo consuetudinario, con el verbo modal ohi = 'soler, tener por costumbre'. Por ejemplo, ikus-ten $d u t=$ 'yo lo/la suelo ver' ha sido sustituido por ikusi ohi $d u t=$ 'yo lo/la suelo ver'. Azkue dice, hablando de estos verbos modales, que «en nuestros días ha adquirido una importancia que antes no tenía una cuestión acerca del auxiliar transitivo e intransitivo correspondiente a estos modales de infinitivo» y cita como ejemplos los siguientes: «etorri ahal naiz puedo venir, y ekarri ahal dut puedo traerlo; ezin etorri naiz no puedo venir, y ezin ekarri dut no puedo traerlo; etorri oi naiz suelo venir, y ekarri oi dut suelo traerlo» (Azkue 1905-1906, I, p. 259). Igualmente, la EMVA del imperativo ha tendido a ser sustituida, simplemente, por el infinitivo (por ejemplo, ikus ezazu = 'vedlo vos' por ikusi = 'ver' o etor zaitez = 'venid vos' se ha sustituido por etorri = 'venir'). El subjuntivo final también se ha tendido a sustituir por el sustantivo verbal en genitivo o en el caso directivo, si es un verbo de movimiento, es decir, con el sufijo -te-ko o -tze-ko, y en los verbos de movimiento, con el sufijo -te-ra. Por ejemplo, ikus dezazun = 'para que vos lo/la veáis' se ha sustituido por zuk ikus-te$k o=$ 'para ver vos', y etor dakizu = 'para que vos vengáis' se ha sustituido por zu etor-te-ra = 'para venir vos'. En la voz pasiva vasca, en cambio, solo se ha utilizado la EMVA, no la ESVP (por ejemplo, aditu-a naiz = "yo soy oído', ekarri-a naiz = 'yo soy traído').

Se puede comprobar, por tanto, la complejísima evolución histórica de la EMVA y de la ESVP vascas, que presenta una sucesión de sustituciones de unas EMV por otras. Las primitivas EMVS han sido sustituidas por las EMVA de origen tardo-latino y algunas de estas últimas por las ESVP. Las EMVA vascas de los tiempos del modo indicativo fueron las que se formaron directamente por analogía con las EMVA tardo-latinas para poder conjugar la gran cantidad de verbos de origen latino que se introdujeron en vasco y, por analogía con las EMVA vascas de indicativo, se formaron las EMVA de todos los tiempos y modos verbales vascos. Las EMVA han sufrido, a su vez, una complejísima evolución histórica, que ha consistido normalmente en la sustitución de sus verbos auxiliares originales, ukan = 'haber' e izan = 'ser' (los mismos que en las lenguas románicas), por otros distintos a ellos y diferentes muchas veces según los dialectos. La mayor evolución histórica es, sin duda, la de las EMV(NDE) tricasuales, que son por ello, además, las que presentan una mayor diversidad dialectal.

\section{REFERENCIAS BIBLIOGRÁFICAS}

Abbadie, A. Th. d' y Chaho de NAvarre, J. A. (1836): Études grammaticales sur la langue euskarienne, París, A. Bertrand.

Alvar, M. y Pottier, B. (1983): Morfología histórica del español, Madrid, Gredos. 
AstarloA, P. P. (1803): Apología de la lengua bascongada ó ensayo crítico filosófico de su perfección y antigüedad sobre todas las que se conocen, Madrid, G. Ortega, reimpr. por Amigos del Libro Vasco, Bilbao, 1983.

Axular, P. de (1643): Gero, Bordeaux, G. Milanges, ed. facsímil en Revista Internacional de Estudios Vascos 4 a 24, hasta cap. XLVII, París y San Sebastián, ed. con introducción y traducción de Luis Villasante, Barcelona, 1964, reimpr. por L. Villasante, Oñati, Jakin, Arantzazu, 1976; reimpr. por Euskaltzaindia, Bilbao, 1988.

Azkarate, M. y Altuna, P. (2001): Euskal morfologiaren historia, San Sebastián, Elkarlanean.

Azkue, R. M. de (1905-1906): Diccionario vasco-español-francés, v. I-II, Bilbao/Tours, A. Mame, reimpr. por La Gran Enciclopedia vasca, Bilbao, 2aㅜ ed, 1969, reimpr. por Euskaltzaindia, Bilbao, 1984.

- (1923-1925): «Morfología Vasca», Euskera 4-6, en Morfología Vasca (gramática básica dialectal del euskera), $2^{\underline{a}}$ ed, Bilbao, La Gran Enciclopedia Vasca, tomos I y II, 1969 .

Bonaparte, L. L. (1869): Le verbe basque en tableaux, Londres, Strangeways y Walden.

CAMPIón, A. (1884): Gramática de los cuatro dialectos literarios del euskara, Tolosa, ed. E. López; reimpr. por La Gran Enciclopedia Vasca, Bilbao, 1977.

Corominas, J. (1954): Diccionario crítico etimológico de la lengua castellana, Madrid, Gredos.

- (1961): Breve Diccionario etimológico de la lengua castellana, Madrid, Gredos, 1973.

- (1980): Diccionari etimològic i complementari de la llengua catalana, Barcelona, Curial.

- y Pascual, J. A. (1980-1991): Diccionario crítico etimológico castellano e hispánico, Madrid, Gredos.

DARRIGOL, J. P. (1827): Dissertation critique et apologétique sur la langue basque, par un ecclesiastique du diocèse de Bayonne, Bayona, Bay Duhart-Fauvet.

DOMENE VERDÚ, J. F. (2007a): Lingüistica y matemáticas: El proceso de formación de la estructura morfológica verbal de la lengua vasca, CD-ROM, Serie Tesis Doctorales, Euskal Herriko Unibertsitatea / Universidad del País Vasco, Servicio de Publicaciones.

- (2007b): «El origen del afijo de plural -it-», Fontes Linguae Vasconum 104, pp. 33-58.

— (2007c): «Los afijos temporales vascos», Fontes Linguae Vasconum 105, pp. 189-217.

- (2007d): «Los modos impersonales del verbo vasco», Fontes Linguae Vasconum 106, pp. 419-453.

- (2007e): «Matematización de la gramática y su aplicación a la estructura morfológica verbal de la lengua vasca», Estudios de Lingüistica de la Universidad de Alicante (ELUA) 21, pp. 65-102.

- (2008a): «El verbo auxiliar trivalente de los dialectos navarro y central», Fontes Linguae Vasconum 107, pp. 151-189.

- (2008b): «El proceso de formación del alocutivo vasco», Fontes Linguae Vasconum 108, pp. 329-364. 
- (2009): Lingüistica y Matemáticas. Axiomatización de la teoría gramatical y su aplicación a la tipología lingüistica, Alicante, Publicaciones de la Universidad de Alicante.

EGIDO FERNÁNDEZ, M. C. (1996): El sistema verbal en el romance medieval leonés, León, Universidad de León, Centro de Estudios Metodológicos e Interdisciplinares.

GAVEL, H. (1929-1937): Grammaire basque, Bayona, Le Courier.

Gómez, R. (1989): «Bonaparte Printzearen inguruko hizkuntz estabaidak», Anuario del Semiario de Filología Vasca «Julio de Urquijo» 23, pp. 355-392.

— y SAINZ, K. (1995): "On the origin of the finite forms of the Basque Verb», en Hualde, J. I., Lakarra, J. A. y Trask, R. L. (ed.), Towards a History of the Basque Language, Serie Current issues in linguistic theory, vol. 131, Amsterdam / Filadelfia, John Benjamins, pp. 235-273.

HARRIET, M. (1741): Gramatica escuaraz eta francesez, composatua francez hitzcunça ikhasi nahi dutenen faboretan, Bayonne, Fauvet.

Herman, J. (1975): El latín vulgar, Barcelona, Ariel, 1997.

Humboldt, W. von (1821): «Examen sobre los aborígenes de España», Revista Internacional de Estudios Vascos 25, pp. 477-475, 26, pp. 44-92 y 499-552, París y San Sebastián, 2ae ed., 1934-1935.

InCHAuspe, E. T. (1858): Le verbe basque, Bayona y París, Lamaignère B. Duprat, reimpr. por Hordago, San Sebastián, 1979.

Lacombe, G. (1924): «La langue basque», en Meillet, A. y Cohen, M. (dir.), Les langues du monde, Génova-París, Editions Slatkine, reimpr. 1981.

Lafitte, P. Abbé (1944): Grammaire basque (Navarro-laburdin littéraire), Bayona, Amis du Musée Basque, 1962, 2ª ed, reimpr. por Elkar, San Sebastián, 1979, reimpr. por Elkar, San Sebastián / Baiona, 1995.

LAFON, R. (1943): Le système du verbe basque au XVIème siècle, 2 vol. Bordeaux, Delmas. Publications de l'Université de Bordeaux, 5. 2 vol, reimpr. por Elkar, San Sebastián, 1980.

LARRAMENDI, M. de, (1729): El impossible vencido. Arte de la lengua bascongada, Salamanca, Antonio Joseph Villagordo Alcaraz, reimpr. por Donostia-Hordago, San Sebastián, 1979.

Michelena, L. (1961): Fonética histórica vasca, San Sebastián, Diputación Foral de Guipúzcoa.

- (1964): Sobre el pasado de la lengua vasca, San Sebastián, Editorial Auñamendi, reimpr. en Sobre historia de la lengua vasca, Anuario del Seminario de Filología Vasca «Julio de Urquijo» 10, Diputación Foral de Guipúzcoa, San Sebastián, 1988.

- (1974): «El elemento latino-románico en la lengua vasca», Fontes Linguae Vasconum 6, 17, Pamplona, pp. 183-209, reimpr. en Michelena, L., Palabras y textos, Vitoria, Universidad del País Vasco, 1987, pp. 195-219.

- (1987a): «Notas sobre compuestos verbales vascos», Revista de Dialectología y Tradiciones Populares 33, 1977, pp. 145-271, reimpr. en Michelena, L., Palabras y textos, Vitoria, Universidad del País Vasco, pp. 311-335.

- (1987b): «Lengua común y dialectos vascos», Anuario del Seminario de Filología Vasca «Julio de Urquijo» 15, 1981, pp. 291-303, reimpr. en Michelena, L., Palabras y textos, Vitoria, Universidad del País Vasco, pp. 35-55.

- (1987c): Palabras y textos, Vitoria, Universidad del País Vasco. 
Micoleta, R. (1653): Modo breve para aprender la lengua vizcayna, Gerona, Dorca, 1880; Ed. Fita, Barcelona, 1888; reimpr. por A. Zelaieta (ed.), Hizkuntza eta Literatura 7, 1988.

Oinenart, A. d' (1656): Notitia utriusque Vasconiae tum Ibericae tum Aquitanicae, $2^{-a}$ ed., París.

Rebuschi, G. (1997): Essais de linguistique basque, Anejo del Anuario del Seminario de Filología Vasca «Julio de Urquijo» 35, San Sebastián, Diputación Foral de Guipúzcoa.

Schuchardt, H. (1893): Baskische Studien über die Enststehung der Bezugsformen des baskischen Zeitworts, Viena, F. Tempsky; Denkschriften der K.K. Akademie der Wissenschaften 43, Wirklichen Mitglieder des Kais. Akademie der Wissenchaften, Wien; reimpr. por Goenaga, A. (trad.), «Sobre la formación de las flexiones de relación del verbo vasco", Boletín de la Real Sociedad Vascongada de Amigos del País XXVIII, 2/3, París-San Sebastián, 1972, pp. 217-337.

- (1923): Primitiae Linguae Vasconum. Einführung ins Baskische, Salamanca, Universidad de Salamanca, 1947.

Trask, R. L. (1977): «Historical syntax and Basque verbal morphology: Two hypotheses», en Douglas, W. A., Etulain, R. W. y Jacobsen, W. H. (eds.), Anglo-American contributions to Basque studies. Essays in honor of Jon Bilbao, Reno, Univ. of Nevada, pp. 203-217.

- (1981): «Basque verbal morphology», Euskalarien Nazioarteko Jardunaldiak, Iker-1, Bilbao, Euskaltzaindia, pp. 285-306.

- (1995): «On the history of the non-finite verb forms in Basque», en Hualde, J. I., Lakarra, J. A. y Trask, R. L. (ed.), Towards a History of the Basque Language, Serie "Current issues in linguistic theory», vol. 131, Ámsterdam / Filadelfia, John Benjamins, pp. 207-234.

VAn Eys, W. J. (1879): Grammaire comparée des dialectes basques, París, Maisonneuve / Londres, Williams and Norgate / Ámsterdam, Frederik Müller.

YrízAr, P. de (1981): Contribución a la dialectología de la lengua vasca, 2 Tomos, San Sebastián, Caja de Ahorros Provincial de Guipúzcoa. 